Research article

\title{
Functional expression of NF I tumor suppressor protein: association with keratin intermediate filaments during the early development of human epidermis
}

\author{
Maria Malminen 1,2, Sirkku Peltonen*1,2, Jussi Koivunen ${ }^{3}$ and \\ Juha Peltonen $1,3,4$
}

Address: ${ }^{1}$ Department of Medical Biochemistry, University of Turku, Turku, Finland, ${ }^{2}$ Department of Dermatology, University of Turku, Turku, Finland, ${ }^{3}$ Department of Anatomy and Cell Biology, University of Oulu, Oulu, Finland and ${ }^{4}$ Department of Dermatology, University of Oulu, Oulu, Finland

E-mail: Maria Malminen - marhen@utu.fi; Sirkku Peltonen* - sirkku.peltonen@tyks.fi; Jussi Koivunen - jkoivune@mail.student.oulu.fi; Juha Peltonen - juha.peltonen@oulu.fi

${ }^{*}$ Corresponding author

Published: 29 August 2002

BMC Dermatology 2002, 2:10
Received: 15 May 2002

Accepted: 29 August 2002

This article is available from: http://www.biomedcentral.com/I47I-5945/2/10

(C) 2002 Malminen et al; licensee BioMed Central Ltd. This article is published in Open Access: verbatim copying and redistribution of this article are permitted in all media for any non-commercial purpose, provided this notice is preserved along with the article's original URL.

\begin{abstract}
Background: NFI refers to type I neurofibromatosis syndrome, which has been linked with mutations of the large NFI gene. NFI tumor suppressor protein, neurofibromin, has been shown to regulate ras: the NFI protein contains a GTPase activating protein (GAP) related domain which functions as P2I rasGAP. Our studies have previously demonstrated that the NFI protein forms a high affinity association with cytokeratin 14 during the formation of desmosomes and hemidesmosomes in cultured keratinocytes.
\end{abstract}

Methods: The expression of NFI protein was studied in developing human epidermis using western transfer analysis, indirect immunofluorescence, confocal laser scanning microscopy, immunoelectron microscopy, and in situ hybridization.

Results: The expression of NFI protein was noted to be highly elevated in the periderm at 8 weeks estimated gestational age (EGA) and in the basal cells at 8-14 weeks EGA. During this period, NFI protein was associated with cytokeratin filaments terminating to desmosomes and hemidesmosomes. NFI protein did not display colocalization with $\alpha$-tubulin or actin of the cytoskeleton, or with adherens junction proteins.

Conclusions: These results depict an early fetal period when the NFI tumor suppressor is abundantly expressed in epidermis and associated with cytokeratin filaments. This period is characterized by the initiation of differentiation of the basal cells, maturation of the basement membrane zone as well as accentuated formation of selected cellular junctions. NFI tumor suppressor may function in the regulation of epidermal histogenesis via controlling the organization of the keratin cytoskeleton during the assembly of desmosomes and hemidesmosomes. 


\section{Background}

The epidermis is derived from the embryonic ectoderm and is first detectable at 4 weeks estimated gestational age (EGA). At this time, the epidermis is composed of two distinct layers of cells. The surface layer, or the periderm, forms the outer limits of the embryo facing the amniotic fluid. Underneath the periderm lies the basal cell layer of the primitive epidermis. The maturation of the epidermis includes development of the intermediate cell layers simultaneously with the maturation of the basement membrane zone between 9 and 16 weeks EGA, shedding of the periderm layer and final maturation into stratified squamous epithelium by the beginning of the third trimester [1-3]. The development of cellular junctions takes place concomitantly with the morphological maturation $[2,4-$ $6]$. These events include the formation of desmosomes, adherens junctions, tight junctions and hemidesmosomes. The formation of cellular junctions is important for the proper development of epidermis, since e.g. conditional ablation of $\alpha$-catenin, a cytoplasmic plaque protein of adherens junctions, in skin results in dramatic alterations in the morphogenesis and differentiation of epidermis [7]. The formation of hemidesmosomes and subsequent attachment of the keratinocytes to the underlying basement membrane is essential for the polarization of the basal cells of epidermis. The protein plaques of contact sites are connected to a specific set of cytoskeletal filaments. Specifically, the junctional proteins of desmosomes and hemidesmosomes are connected to intermediate filaments while adherens and tight junctions are linked with actin microfilaments.

NF1 refers to type 1 neurofibromatosis syndrome, which has been linked with mutations of the large NF1 gene [810]. The hallmarks of NF1 include café au lait pigment spots of the epidermis, skin freckling, cutaneous neurofibromas, and Lisch nodules of the iris $[9,11]$. Other findings often associated with NF1 include learning disabilities, varying osseous dysplasias, optic pathway gliomas and predisposition to malignancies. Molecular cloning of the entire coding sequence of the NF1 gene and subsequent analysis of the corresponding peptide sequence has lead to recognition of NF1 protein (neurofibromin) as a regulator of ras, or p21 rasGAP $[8,10,12,13]$. NF1 protein regulates the levels of biologically active rasGTP. Ras activity is associated with the regulation of cell growth and differentiation, including control of cytoskeletal organization and formation of cell-cell junctions $[7,14]$. The NF1 protein has been referred to as a tumor suppressor as cells of malignant peripheral nerve sheath tumors of neurofibromatosis patients may display loss of heterozygosity of the NF1 gene [15]. In addition, somatic mutations of NF1 gene have also been found in colon adenocarcinoma, myelodysplastic syndrome, and anaplastic astrocytoma tissues of otherwise healthy persons $[16,17]$.
Furthermore, the levels of NF1 protein and/or mRNA have been reported to be altered in certain proliferative diseases, such as transitional cell carcinoma, basal cell carcinoma, astrocytoma, pheochromocytoma, meningioma, and psoriasis [18-22].

Several studies implicate that NF1 protein has a crucial role during the development. Mice carrying a homozygous null mutation at the NF1 locus die in utero apparently due to the severe malformations in heart [23]. Unlike in adult tissues, NF1 protein is ubiquitously expressed during the development. The expression level and pattern of NF1 protein have been noted to change markedly and rapidly during the development in mice and men $[24,25]$. These rapid changes have been considered to be related to some of the major morphological changes occurring in tissues e.g. heart $[26,27]$.

In order to reveal the functions of NF1 protein at the molecular level, interactions of the NF1 protein with cytoskeletal and plasma membrane components have been studied. Recent keratinocyte culture studies have demonstrated that the NF1 tumor suppressor factor forms a high affinity association with cytokeratin 14 during the short period when the formation of desmosomes and hemidesmosomes takes place [28]. NF1 protein becomes rapidly associated with intermediate filament cytoskeleton (cytokeratin 14), desmoplakin, and $\beta 4$ integrin, when cultured human keratinocytes are induced to differentiate and form cell-cell junctions by increasing $\mathrm{Ca}^{2+}$ concentration of the cell culture medium. On the other hand, Li et al. [29] have demonstrated differential localization of the NF1 gene product with the F-actin or microtubule cytoskeleton during the differentiation of telencephalic neurons. Furthermore, Hsueh et al. [30] have demonstrated that NF1 tumor suppressor can form a bipartite interaction with transmembrane proteoglycans syndecans 1-4.

The purpose of the present study was to investigate the interactions of NF1 protein with cytoskeleton during the morphogenesis of human epidermis. Developing epidermis provided a unique opportunity to visualize cytoskeletal and junctional proteins together with NF1 protein in vivo. The results indicated interaction of NF1 protein with cytokeratin 14 during the polarization of basal cells and the maturation of intercellular junctions.

\section{Methods}

\section{Tissue samples and keratinocyte cell cultures}

Skin samples from 15 normal fetuses aged 8, 10, 10, 11, $12,12,13,13,14,14,15,16,17,18$ and 21 gestational weeks were obtained from the Department of Obstetrics and Gynecology, University Hospital of Turku, Finland. A sample of neonatal skin was obtained from the Department of Pathology, University of Turku, Finland. Adult 
skin samples were obtained from plastic surgical operations carried out for cosmetic reasons from healthy persons at the University Hospital of Turku, Finland. All the tissue samples were obtained with the appropriate approval of the Joint Ethical Committee of the University Hospital of Turku and the University of Turku, Finland. The tissue samples were used for the following experiments. Primary cultures of normal human keratinocytes were established from adult skin samples and cultured as described earlier by Pummi et al. [6].

\section{Primary antibodies}

A commercial polyclonal affinity-purified rabbit antibody NF1GRP(D) raised against synthetic peptide corresponding to amino acids $2798-2818$ of the predicted NF1 gene product was used for Western blotting, indirect immunofluorescence, immunoelectron microscopy, avidin-biotin immunolabeling, and coimmunoprecipitation (sc67, Santa Cruz Biotechnology, Santa Cruz, CA) [8]. The dilution used for indirect immunofluorescence varied from 1:10 in neonatal and adult skin to 1:500 in fetal samples. Other antibodies specific for NF1 protein were the affinity-purified polyclonal NF1ab67 recognizing a peptide sequence encoded by exon 23a and the polyclonal antiserum NF1as159 recognizing a peptide sequence at the carboxyterminal end of NF1 protein. These antibodies have been characterized earlier by Hermonen et al. [20] and Koivunen et al. [28]. Other primary antibodies used in indirect immunofluorescence were mouse monoclonal antibodies to human E-cadherin (13-1700; Zymed Laboratories Inc., San Francisco, CA); actin (1378 996) and desmoplakin I and II (881 147) both from Boehringer Mannheim Biochemica, Mannheim, Germany; $\alpha$-actinin (A-5044), cytokeratin 14 (C-8791), and $\alpha$-tubulin (T9026) from Sigma Chemical Company, St. Louis, MO; $\beta 4$ integrin (12088-019, Gibco BRL Life Technologies Inc.); and syndecan-1 (CD138, MCA681H, Serotec, Kidlington, UK).

\section{Western transfer analysis}

Cultured keratinocytes, adult epidermal and fetal skin samples were homogenized in RIPA buffer [ $1 \%$ Igepal CA$630,0.5 \%$ sodium deoxycholate, and $0.1 \%$ sodium dodecyl suphate (SDS) in phosphate buffered saline (PBS)] supplemented with protease inhibitors (Complete, Mini, EDTA-free Protease Inhibitors Cocktail Tablets, Boehringer Mannheim $\mathrm{GmbH}$ ). Protein concentrations of soluble fraction were detected with DC Protein Assay (Bio-Rad Laboratories, Hercules, CA). $40 \mu \mathrm{g}$ of cultured keratinocyte and fetal preparations and $80 \mu \mathrm{g}$ of adult epidermal preparation were loaded on 6\% SDS polyacrylamide gel. After electrophoresis, proteins were transferred to Immobilon-P filter (Millipore Corporation, Bedford, MA) and immunolabeled with NF1GRP(D) antibody at the dilution of 1:1000. Peroxidase-linked donkey-anti-rabbit (NA
934) (Amersham International plc, Little Chalfont, Buckinghampshire, England) was used as secondary antibody at the dilution of 1:10 000. Proteins were detected with ECL (Amersham Life Sciences, Little Chalfont, England) and the filter was exposed to autoradiographic film (Eastman Kodak, New York, NY).

\section{Co-immunoprecipitation}

Cultured keratinocytes were extracted with CB-buffer (Coimmunoprecipitation buffer: 20 mM Tris, pH 7.4, 150 $\mathrm{mM} \mathrm{NaCl}, 0.5 \%$ Igepal CA-630, and Complete, Mini, EDTA-free Protease Inhibitors Cocktail Tablets, Boehringer Mannheim) and the protein concentrations of soluble fraction were detected with DC Protein Assay (Bio-Rad Laboratories). $650 \mu \mathrm{g}$ of the cell lysate was used for the coimmunoprecipitation. The lysate was first precleared with $50 \mu \mathrm{l}$ of G-sepharose (Boehringer Mannheim) for 3 $\mathrm{h}$ and centrifuged. $10 \mu \mathrm{l}$ of antibody for syndecan- 1 (0.1 $\mathrm{mg} / \mathrm{ml}$ ) was added to the supernatant and incubated for 1 h. $50 \mu \mathrm{l}$ of G-sepharose was added and further incubated for $12 \mathrm{~h}$. The lysate was centrifuged and the pellet was washed with CB-buffer for four times. Precipitated proteins were separated from the sepharose by adding Laemmli buffer and boiling the sample for $4 \mathrm{~min}$. After centrifugation, the supernatant was loaded on SDS polyacrylamide gel, electrophoresed, transferred to Immobilon-P filter, immunolabeled with NF1GRP(D), and detected with ECL as described above with Western blotting.

\section{Indirect immunofluorescence and confocal laser scanning microscopy}

Indirect immunofluorescence labeling of frozen fetal, neonatal, and adult skin sections and confocal laser scanning microscopy of these labelings were performed as described earlier by Pummi et al. [6]. Frozen sections of fetal, neonatal and adult skin were cut on silanated glass slides. Samples were fixed with $100 \%$ methyl alcohol and preincubated in PBS supplemented with $1 \%$ bovine serum albumin (BSA). The primary antibodies were diluted in $1 \%$ BSA-PBS, and incubated on the samples at $4^{\circ} \mathrm{C}$ for $20 \mathrm{~h}$. After several washes in PBS, the slides were incubated with secondary antibodies at $20^{\circ} \mathrm{C}$ for $1 \mathrm{~h}$. The samples were washed in PBS and mounted with Glycergel (Dako, Glostrup, Denmark). The secondary antibody used for indirect immunofluorescence was tetramethylrhodamine isothiocyanate (TRITC) conjugated swine anti-rabbit IgG (R0156, Dako A/S). In double labelings, TRITC-conjugated swine anti-rabbit IgG was mixed with fluorescein isothiocyanate (FITC)-conjugated $\mathrm{F}\left(\mathrm{ab}^{\prime}\right)_{2}$ fragment of goat anti-mouse immunoglobulins (F0479, Dako A/S) or Alexa Fluor $^{\mathrm{TM}} 488$ conjugated goat anti-mouse IgG (Molecular Probes, Eugene, OR). Alternatively, FITC-conjugated swine anti-rabbit IgG (F0205, Dako A/S) was mixed with TRITC-conjugated goat anti-mouse IgG $(\mathrm{H}+\mathrm{L})(115-025$ - 
146, Jackson ImmunoResearch Laboratories Inc., West Grove, PA). Confocal laser scanning microscopy was carried out using Leica TCS SP Spectral confocal laser scanning microscope equipped with an air-cooled ArgonKrypton ion-laser system (Leica Microsystems Heidelberg GmbH, Heidelberg, Germany) and Leica TCS NT software (Version 1.6.551 Heidelberg, Germany).

\section{Immunoelectron microscopy}

The immunoelectron microscopy was performed using a post-embedding method as described earlier by Pummi et al. [6]. In short, $1 \times 1 \mathrm{~mm}$ pieces of fetal skin were fixed with $4 \%$ paraformaldehyde and embedded in L.R. White resin (London Resin Company Limited, Berkshire, England). NF1GRP(D) (dilution 1:100) was used as primary antibody and goat-anti-rabbit IgG coupled to $12 \mathrm{~nm}$ gold particles (Jackson ImmunoResearch Laboratories Inc.) was used as secondary antibody at the dilution of 1:30. The sections were examined and photographed using JEOL 1200SX electron microscope.

\section{Avidin-Biotin immunolabeling}

Formalin fixed and paraffin-embedded specimens were immunolabeled with avidin-biotin method using Histostain-Plus Kit (Zymed Laboratories Inc.) according to the protocol supplied with the kit by the manufacturer. NF1GRP(D) was used as the primary antibody at the dilution of 1:200. 3.3'-diaminobenzidine tetrahydrochloride (DAB-Plus Kit, Zymed Laboratories Inc.) was used to visualize the antibody localization. Slides were counterstained with Mayer's haematoxylin (Oy Reagena LTD, Kuopio, Finland).

\section{In situ hybridization}

In situ hybridization was performed as described previously in detail by Ylä-Outinen et al. [31]. In short, a 650 bp mouse NF1 cDNA fragment corresponding to bases 230880 of human NF1 cDNA (acc:M89914) was used as a template for the synthesis of digoxigenin labeled sense and antisense cRNA probes. Paraffin-embedded fetal skin sections were deparaffinized, pretreated with $0.2 \mathrm{M} \mathrm{HCl}$, washed in $2 \mathrm{mg} / \mathrm{ml}$ glysin-PBS, and acetylated in $0.1 \mathrm{M}$ triethanolamine (pH 8.0) $0.25 \%$ acetic anhydride solution. Slides were heated to $90^{\circ} \mathrm{C}$ for $5 \mathrm{~min}$, cooled over ice, and prehybridized in solution containing 50\% formamide, $0.6 \mathrm{M} \mathrm{NaCl}, 2 \mathrm{mM}$ Tris-HCl, pH 7.4, 1 mM EDTA, $1.0 \mathrm{mg} /$ ml BSA, 0.02\% PVP, 0.02\% Ficoll, $10 \mathrm{mM}$ DTT, $0.2 \mathrm{mg} /$ $\mathrm{ml}$ ssDNA, and $10 \%$ dextran sulphate. Hybridization was performed at $45^{\circ} \mathrm{C}$ overnight in a mixture containing prehybridization solution and $300 \mathrm{ng}$ of cRNA probe for each sample. All samples were prepared as duplicate and hybridized separately with sense and antisense probes.

After hybridization, the samples were washed in $4 \times$ SSC and unbound RNA probe was removed with RNase treat-

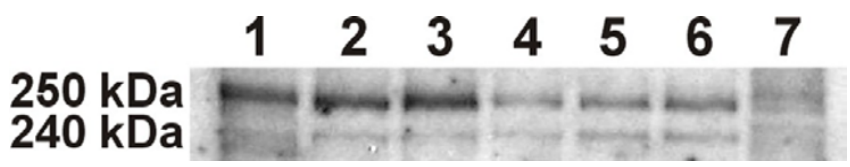

Figure I

Western transfer analysis of fetal skin and adult epidermis with NFI GRP(D) antibody. Lane I: cultured human keratinocytes $(40 \mu \mathrm{g})$. Lanes 2-3: I2-week-old fetal skin (40 $\mu \mathrm{g})$. Lanes 4-5: 13-week-old fetal skin $(40 \mu \mathrm{g})$. Lane 6: I4-weekold fetal skin $(40 \mu \mathrm{g})$. Lane 7 : adult epidermis $(80 \mu \mathrm{g})$. The analysis reveal typical 240 and $250 \mathrm{kDa}$ bands representative of NFI protein.

ment. The samples were washed to the final stringency of $0.1 \times$ SSC, $1 \mathrm{mM}$ EDTA, and $1 \mathrm{mM}$ DTT at $45^{\circ} \mathrm{C}$. DIG-labeled cRNA probe was detected with sheep anti-digoxigenin antibody (dilution 1:100) coupled to alkaline phosphatase (Roche Diagnostics), which was used with color forming substrate solution according to the protocol provided by manufacturer.

\section{Results}

The expression of NF1 protein in epidermis and in cultured keratinocytes was first assessed by western transfer analysis. The results revealed two bands of $240 \mathrm{kDa}$ and $250 \mathrm{kDa}$ representative of NF1 protein in all samples, although the band of $240 \mathrm{kDa}$ was less prominent in cultured keratinocytes (Fig 1, lane 1) and in adult epidermis (Fig 1, lane 7) compared to the fetal skin samples (Fig 1, lanes 2-6). 240 and $250 \mathrm{kDa}$ bands positive for NF1 protein in western transfer analysis have earlier been described in other tissues, also $[8,27,32]$. The expression level of the NF1 protein was higher in cultured keratinocytes and fetal skin samples compared to the adult epidermis.

Indirect immunofluorescence labeling and confocal laser scanning microscopy (CLSM) was effective in visualizing NF1 protein in different layers of the epidermis, and in demonstrating variable subcellular distribution patterns of the protein within individual cells. At 8 weeks EGA, epidermis consisted of two cell layers, the basal and the periderm layers. Both cell layers were intensely labeled with the $\mathrm{C}$ terminus-specific antibody NF1GRP(D) which revealed a fibrillar labeling pattern (Fig 2a). The periderm cells displayed a more intense immunosignal compared to the basal cells at this two-layer stage of epidermal development. A third, the intermediate, cell layer was detectable between the basal and the periderm cell layers at 11 weeks EGA (Fig 2b). All three cell layers were positive for NF1 protein. The labeling pattern remained fibrillar in the basal cells, while labeling of periderm cells had changed into a diffuse distribution within the cytoplasm. Cells of 


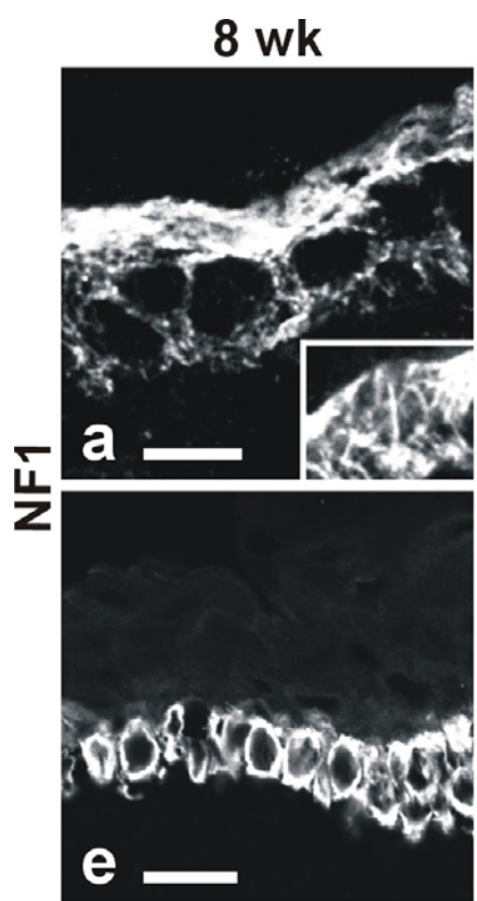

21 wk

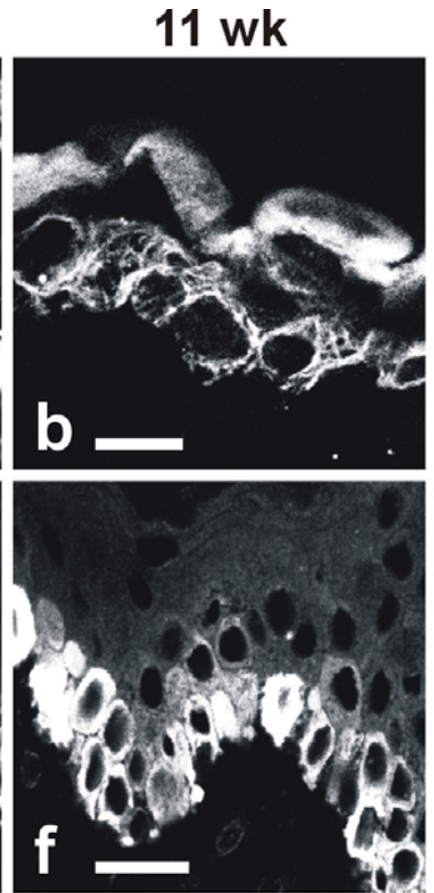

NB
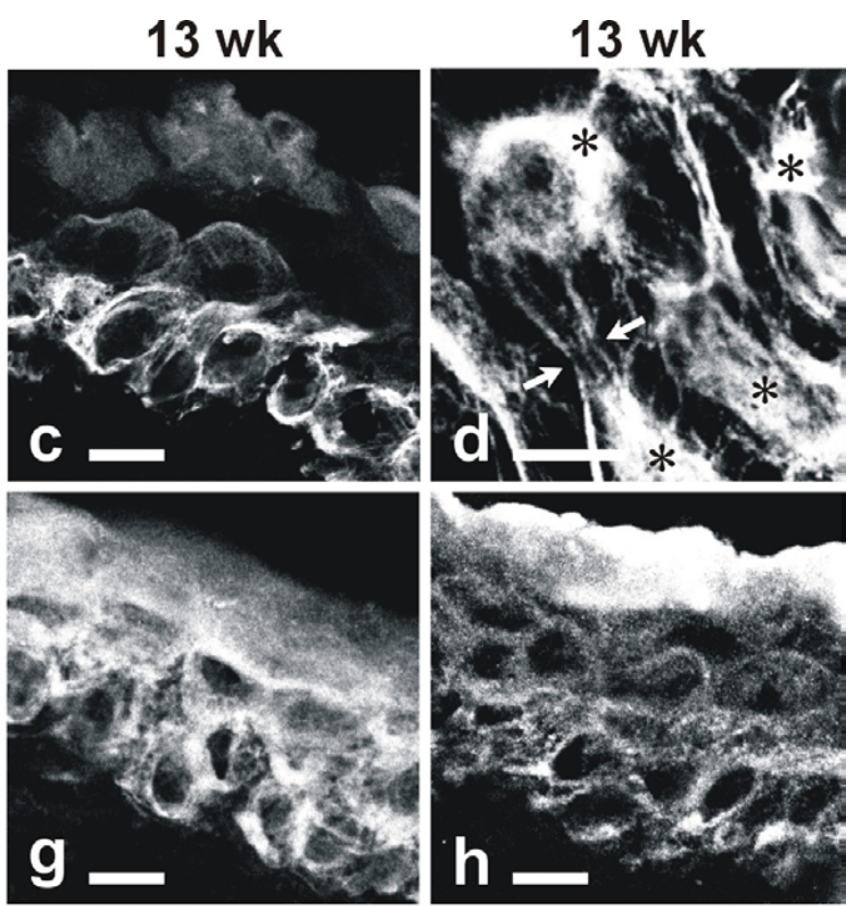

NF1as159; 14 wk NF1ab67; 14 wk

\section{Figure 2}

Indirect immunofluorescence labeling and CLSM analysis of developing human epidermis for NFI protein. (a-f) Labeling with NFIGRP(D) antibody (dilution of I:500 in fetal samples and dilution of I:I0 in neonatal (NB) sample). (a) At 8 weeks EGA, developing epidermis consists of basal and periderm cell layers. Both cell layers are intensely labeled and reveal a fibrillar labeling pattern. Insert: higher magnification of cytoplasmic compartment of a periderm cell. (b) At II weeks EGA, an intermediate cell layer is detectable between the basal and the periderm cell layers. The basal cells show a fibrillar labeling pattern, while labeling of periderm cells is diffuse. The intermediate layer shows less intense immunoreaction for NFI protein. (c) At I 3 weeks EGA, the suprabasal epidermis consists of multiple cell layers. The basal cells show fibrillar labeling pattern for NFI protein while the periderm cells are characterized with a diffuse and faint immunoreaction. (d) A transverse section of basal cells at 13 weeks EGA. Cells have a perinuclear web of fibrils positive for NFI protein $(*)$. Some fibrils are directing towards desmosomes (arrows) (see also figure 5B, a and c). (e,f) In 21 -week-old and in neonatal (NB) epidermis the basal cells show diffuse cytoplasmic labeling for NFI protein. (g) NFI specific antiserum NFI as I 59 labels all epidermal cell layers at I4 weeks EGA. The labeling is fibrillar in the basal cells. (h) Also NFI specific antibody NFIab67 labels all cell layers, but in a more punctuate manner. Scale bars $10 \mu \mathrm{m}$ in a-c, g, h; $5 \mu \mathrm{m}$ in d; $20 \mu \mathrm{m}$ in e, f. Insert in (a) $30 \mu \mathrm{m}$.

the intermediate layer showed less intense immunoreaction for NF1 protein.

At 13 weeks EGA, the basal cells retained the fibrillar labeling pattern with NF1GRP(D) antibody (Fig 2c). Analyses of the transverse sections of the basal cells were particularly informative. Specifically, the results demonstrated that NF1 antibody labeled a web of fibrils extending from a perinuclear location towards the cell periphery and desmosomes (Fig 2d; see also Fig 5B:c). At 13 weeks EGA, the periderm cells revealed a faint and a more diffuse labeling pattern for the NF1 compared to the basal cells (Fig 2c). Samples of 14 weeks EGA were also labeled with two other NF1 specific antibodies (NF1as159 and NF1ab67) (Fig 2g,2h). Both antibodies labeled all three types of epidermal cell layers. The NF1as159 antibody showed a fi- brillar pattern in the basal cell cytoplasm (Fig 2g). NF1 isoform type II specific antibody ab67 labeled all cell layers in a more punctuate manner (Fig 2h). Between 13 and 15 weeks EGA, the expression of NF1 protein faded out in periderm cells (data not shown).

Four distinct layers of epidermis, the basal, the spinous, the granular, and the cornified cell layers were detectable at 21 weeks EGA. The periderm cells had disappeared by that time. By 21 weeks EGA and in the neonatal human epidermis, the fibrillar labeling for the NF1 protein in basal cells was no longer detectable. The labeling pattern had changed from fibrillar into more diffuse cytoplasmic staining (Fig 2e,2f). Even the highest magnifications failed to reveal the fibrillar labeling (not shown). 


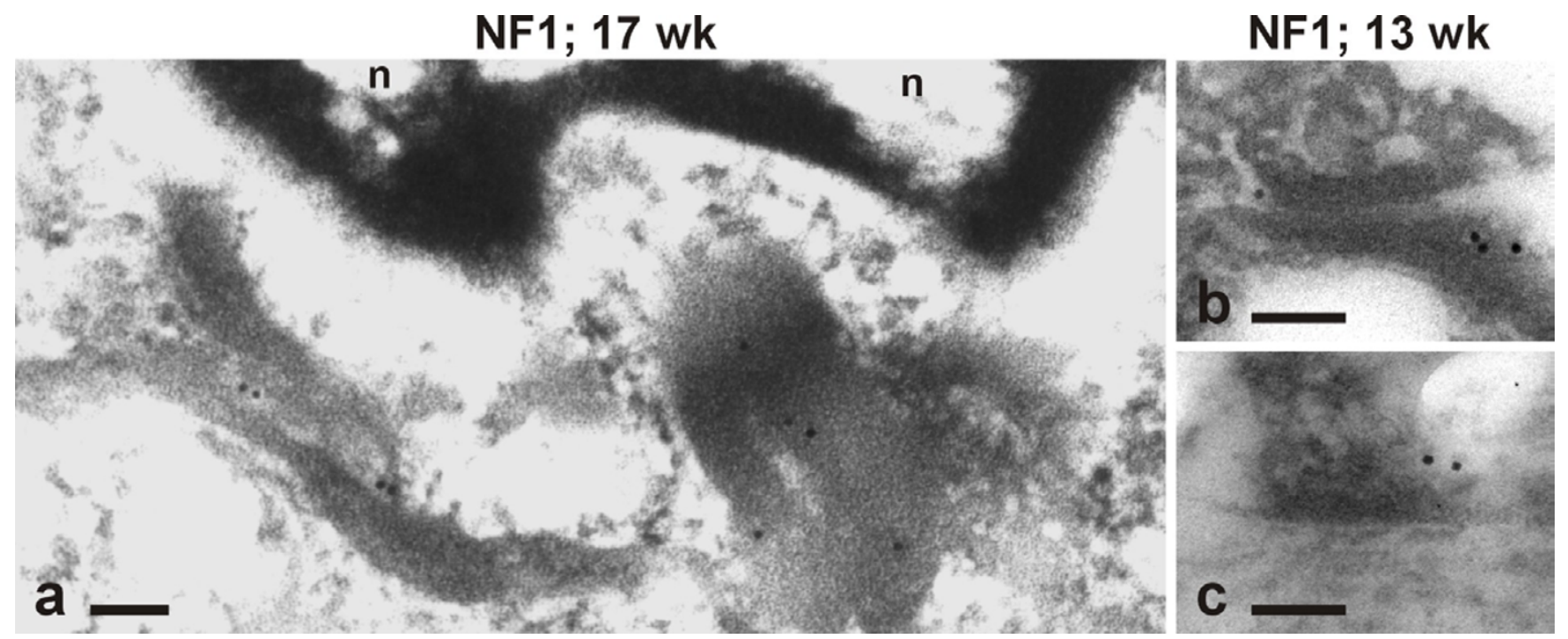

Figure 3

Immunoelectron microscopy of the developing human epidermis with NFIGRP(D) antibody. Gold particles representative of NFI protein are located on the cytokeratin filaments (a) circumscribing the nucleus (n), (b) terminating to a desmosome, and (c) to a hemidesmosome. Scale bars $100 \mathrm{~nm}$.

In order to localize NF1 protein at the ultrastructural level, post-embedding immunoelectron microscopy of developing skin was performed using NF1GRP(D) antibody. The results revealed that in basal keratinocytes, the NF1 protein was located on the bundles of cytokeratin filaments, which formed a tight web around the nucleus (Fig $3 a)$. Gold particles representative of NF1 protein were detected also on cytokeratin filaments terminating to desmosomes (Fig 3b) and hemidesmosomes (Fig 3c).

In further analyses, the expression of NF1 gene was studied by in situ hybridization and avidin-biotin immunolabeling of paraffin embedded samples. Avidin-biotin immunolabeling revealed a pattern corresponding to that detected by indirect immunofluorescence. At 13 weeks EGA, the basal and the periderm cell layers were intensely labeled with the NF1GRP(D) antibody (Fig 4a). Also the intermediate cells showed positive reaction located in the cell periphery. At 18 weeks EGA, the basal cell layer revealed the most intense labeling while the other layers were less positive (Fig 4d). In situ hybridization revealed NF1 mRNA in developing epidermis. At 13 weeks EGA, NF1 mRNA was noted in the basal and intermediate cell layers (Fig 4c). Subcellularly, NF1 mRNA was located at the basal aspect of basal cells and at the cell periphery of intermediate cells. At 18 weeks EGA, NF1 mRNA was detectable near the cell membranes in the suprabasal cell layers, while the basal cells expressed NF1 mRNA at a very low level (Fig 4f).
To investigate the fibrillar labeling pattern of NF1 protein in early developing epidermis in more detail, double immunolabelings with NF1 protein and cytoskeletal marker proteins were carried out. At 13 weeks EGA, cytokeratin 14 antibody labeled cytoskeletal intermediate filaments of the basal cells (Fig 5A:a,d). Some labeling was also noted in the periderm. Immunosignals for the NF1 protein and cytokeratin 14 showed marked colocalization on many locations in basal cells (Fig 5A:a,d). Actin antibody labeled the peripheral cytoplasm of all epidermal and periderm cells (Fig 5A:b,e). As the NF1 protein positive fibrils were located closer to the nuclei and actin labeling was detected more peripherally, these two components showed separate labeling (Fig 5A:b,e). $\alpha$-tubulin antibody labeled also all epidermal cell layers, but did not colocalize with NF1 protein (Fig 5A:c,f).

In order to evaluate the spatial relationship of NF1 positive cytokeratin fibrils with desmosomes and hemidesmosomes, double immunolabelings of NF1 protein with desmosomal and hemidesmosomal marker proteins were carried out. At 13 weeks EGA, desmoplakin, a desmosomal cytoplasmic plaque protein, was present in a typical punctuate pattern at the cell-cell junction sites in all cell layers (Fig 5B:a). However, the intercellular junction sites of basal cells showed weaker labeling for desmoplakin. Higher magnification revealed that NF1 positive cytokeratin fibrils terminated to dots of desmoplakin (Fig 5B:c). Antibody for $\beta 4$ integrin, a transmembrane component of hemidesmosomes, labeled the basal aspects of the basal cells as distinct dots (Fig 5B:b,d). Higher magnification re- 
NF1 protein
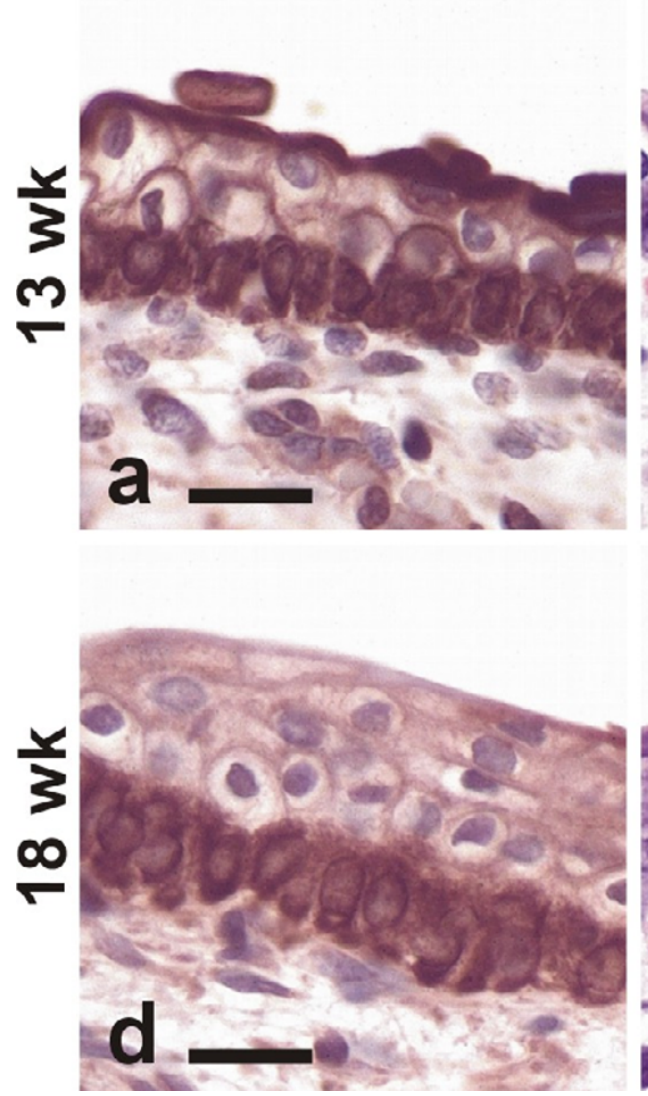

HE
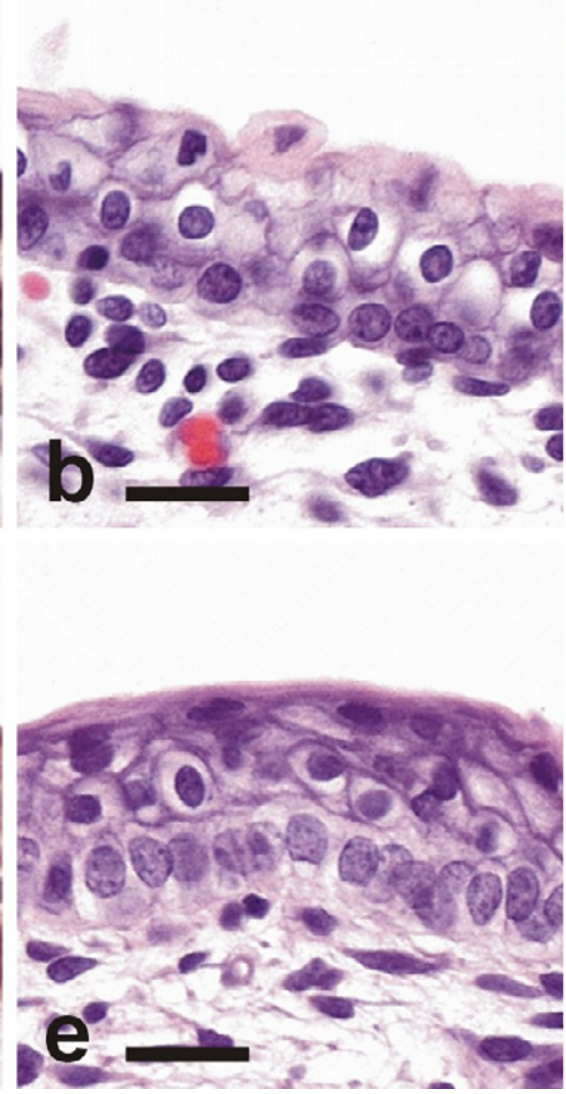

\section{mRNA in situ}
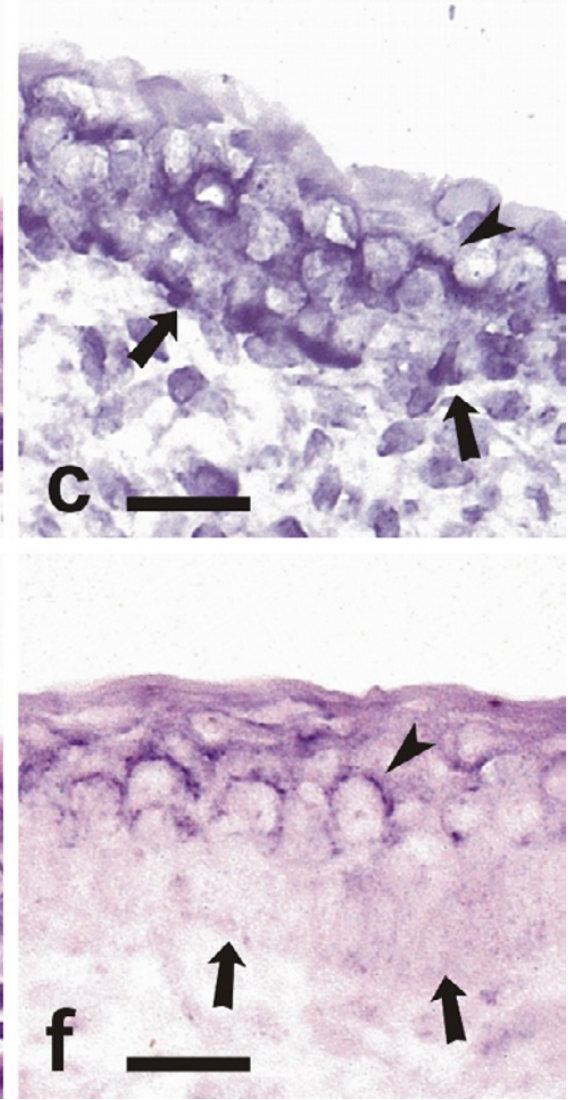

Figure 4

Avidin-biotin immunolabeling of NFI protein and in situ hybridization of NFI mRNA in developing human epidermis. (a) At I 3 weeks EGA, the basal and the periderm cell layers are intensely labeled with the NFIGRP(D) antibody. Also intermediate cells show positive reaction near cell membranes. (b) Hematoxylin-eosin staining of developing epidermis at I 3 weeks EGA. (c) NFI mRNA is noted in the basal and intermediate cell layers at 13 weeks EGA. Subcellularly, NFI mRNA is located at the cell periphery of intermediate cells (arrowhead). Note the positive NFI mRNA signal at the basal aspect of basal cells at this stage of development. Arrows point to the basement membrane zone. (d) At 18 weeks EGA, the basal cells display the most intense immunoreaction with NFIGRP(D) antibody. (e) Hematoxylin-eosin staining of I8-week-old epidermis. (f) At 8 weeks EGA, NFI mRNA is detectable only in the suprabasal cell layer by in situ hybridization. The positive NFI mRNA signal is located near cell membranes (arrowhead). Arrows point to the basement membrane zone. Scale bars $20 \mu \mathrm{m}$.

vealed that NF1 positive cytokeratin fibrils were directed towards the $\beta 4$ integrin dots (Fig 5B:d). By 16 weeks EGA, labeling of $\beta 4$ integrin was intensified and changed into a more linear labeling pattern (not shown).

The localization of NF1 protein and selected adherens junction proteins were investigated using double immunolabelings in developing epidermis at 13 weeks EGA. Ecadherin antibody revealed the cell-cell junction sites of the basal and intermediate cells (Fig 5C:a), but high magnification showed that the immunosignals for E-cadherin and NF1 protein were not colocalized (Fig 5C:d). Also, $\alpha-$ actinin and NF1 protein were mutually exclusive (Fig $5 C: b, e) . \beta 1$ integrin labeled the cell membranes of the ba- sal cells, including the basal aspect of basal cells (Fig $5 \mathrm{C}: \mathrm{c})$. Higher magnification showed that NF1 protein positive fibrils were terminating between the $\beta 1$ integrin labeling at cell-cell junction sites (Fig 5C:f). Thus, immunosignals for NF1 protein and adherens junction components were separate.

Recent data by Hsueh et al. [30] demonstrated interaction of NF1 protein and syndecans 1-4. To evaluate whether these proteins were in close contact in keratinocytes, double immunolabeling was performed. In developing epidermis at 14 weeks EGA, syndecan-1 was localized to the plasma membrane of keratinocytes in all epidermal layers (Fig 6a). Potential colocalization or close spatial relation- 


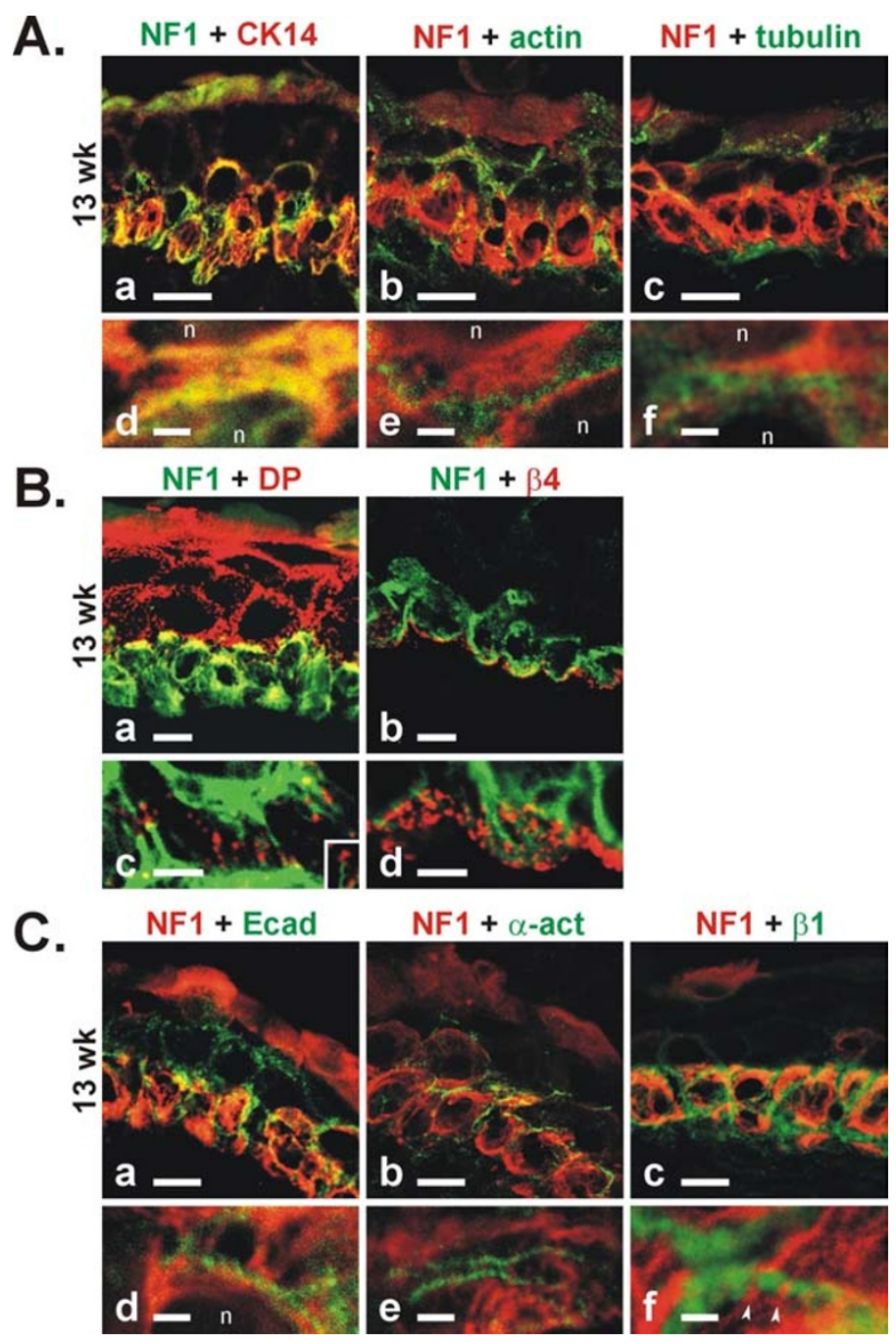

Figure 5

A. Double immunolabeling and CLSM analysis of NFI protein with NFIGRP(D) antibody and cytoskeletal marker proteins at 13 weeks EGA in developing human epidermis. (a) NFI protein (green) and cytokeratin I4 (red) show colocalization (yellow) on many locations of the basal cells. (d) High magnification reveals a marked degree of colocalization of NFI protein and cytokeratin I 4 labeling patterns. (b) NFI protein (red) and actin (green) antibodies show separate labeling patterns. (e) Higher magnification reveals that the NFI positive fibrils (red) are located closer to the nuclei (n), while actin (green) is located more peripherally. (c) NFI protein (red) and $\alpha$-tubulin (green) antibodies show separate labeling. (f) High magnification of labeling for $\alpha$-tubulin and NFI protein. Scale bars $10 \mu \mathrm{m}$ in a-c, I $\mu \mathrm{m}$ in $\mathrm{d}$-f. B. Double immunolabeling and CLSM analysis for NFI protein with NFIGRP(D) antibody and desmoplakin or $\beta 4$ integrin in developing human epidermis at I 3 weeks EGA. (a) Desmoplakin (red) is present in all epidermal cell layers, although the basal cells show weaker labeling. Instead, NFI-specific antibody labels the basal and the periderm cells. (c) Higher magnification reveals that cytokeratin fibrils associated with NFI protein (green) terminate to spots of desmoplakin (red) indicating the location of desmosomes. Insert in (c) show the location of a desmoplakin dot (red) at the end of a NFI positive fibril (green). (b) $\beta 4$ integrin (red) label the basal aspect of the basal cells, while NFI protein (green) label the basal cell cytoplasm. (d) Higher magnification reveals that $\beta 4$ integrin dots (red) are located at the end of NFI positive fibrils (green). Scale bars $10 \mu \mathrm{m}$ in a, b; $2 \mu \mathrm{m}$ in c, d. C. Double immunolabeling and CLSM analysis of NFI protein with adherens junction proteins and $\alpha$-actinin in developing human epidermis at I3 weeks EGA. (a) E-cadherin antibody (green) labels the cell-cell junctions of the basal and intermediate cells. NFIGRP(D) antibody (red) show basal and periderm cell cytoplasmic labeling. (d) Higher magnification reveals that immunosignals for E-cadherin (green) and NFI protein (red) are not colocalized. (b and e) Also $\alpha$-actinin (green) and NFI (red) are seen mutually exclusive. (c) $\beta I$ integrin (green) labels the cell membranes of the basal cells, while NFI protein (red) labeling is cytoplasmic. (f) In higher magnification, NFI positive fibrils (red; arrowheads) are terminating between the $\beta I$ integrin labeling (green) at cell-cell junction sites. $n$, nucleus. Scale bars $10 \mu \mathrm{m}$ a-c; I $\mu \mathrm{m}$ in d-f. 

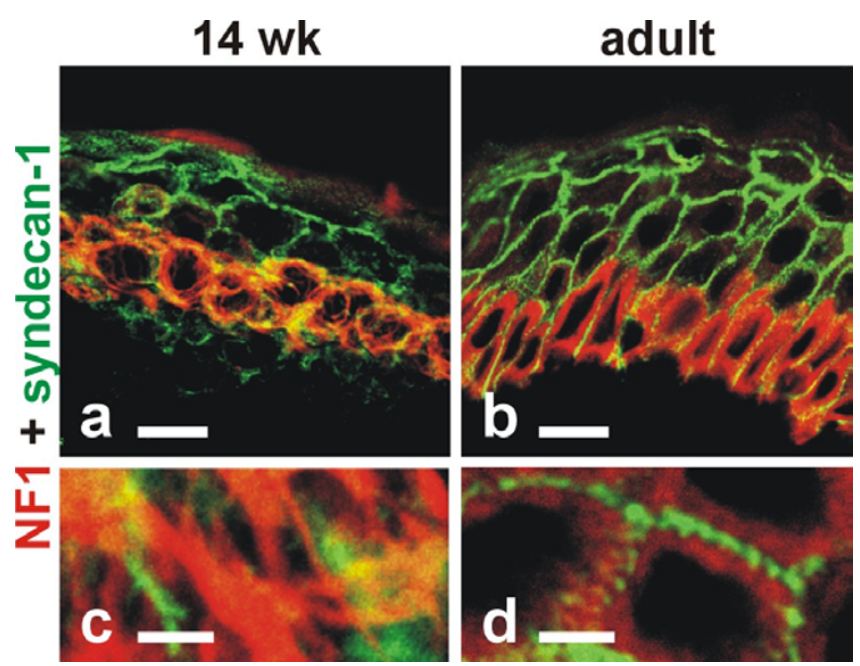

Figure 6

Double immunolabeling and CLSM analysis of developing and adult epidermis for NFI protein and syndecan-I. (a) At I4 weeks EGA, the NFI protein (red) shows fibrillar pattern in basal cells while syndecan-I (green) is localized to the plasma membrane of keratinocytes in all epidermal layers. Close spatial distribution or colocalization (yellow) is detected on some basal cells. (b) In adult epidermis the immunosignals for the NFI protein (red) and syndecan-I (green) are completely separate. Scale bars $10 \mu \mathrm{m}$ in a,b, $2 \mu \mathrm{m}$ in c,d.

ship of syndecan-1 with NF1 protein was noted on some basal cells (Fig 6a,6c). However, in adult epidermis, immunosignals for the NF1 protein and syndecan-1 were entirely separate (Fig 6b,6d). Immunoprecipitation of keratinocyte culture lysates with syndecan-1 specific antibody and subsequent western analysis with NF1GRP(D) antibody demonstrated that syndecan- 1 was connected to a small fraction of NF1 protein (Fig 7).

\section{Discussion}

The results of the present study demonstrate an early fetal period when the NF1 tumor suppressor is abundantly expressed and associated with bundles of intermediate filaments of the basal keratinocytes. This emphasizes that the NF1 gene is developmentally regulated also in human skin. These findings also strengthen the view that the large NF1 protein exerts its functions through multiple molecular interactions. Specifically, NF1 tumor suppressor factor associates and functions with proteins located with the plasma membrane (p21ras, syndecans), or with cytoskeletal components associated with selected cellular junctions (desmosomes, hemidesmosomes) [12,28,30]. The action of NF1 protein may be analogous to e.g. fatty acid synthase, which conducts its tasks using different sites of the same molecule. It should also be noted that the activity of ras is associated with the regulation of cell growth

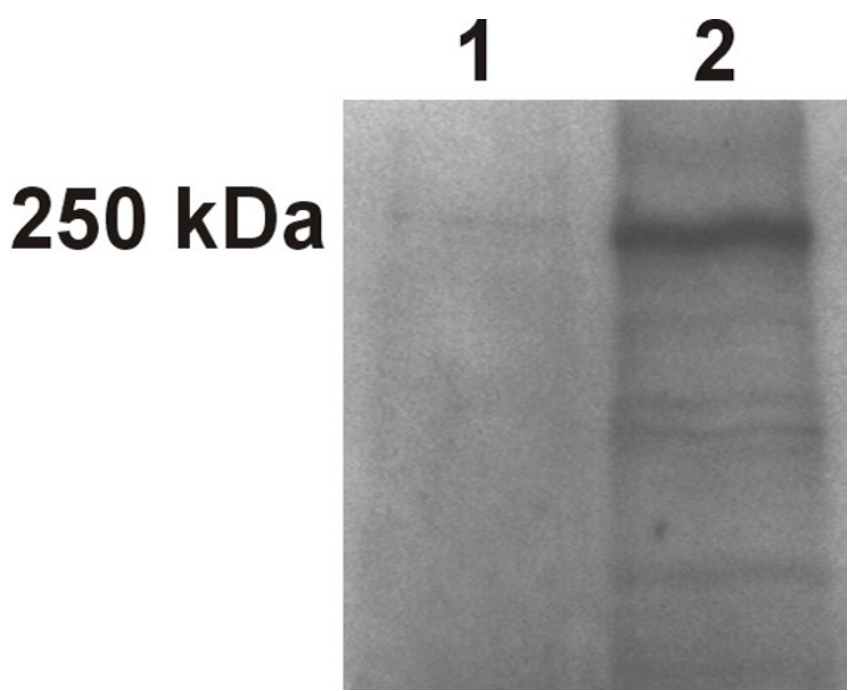

\section{Figure 7}

Coimmunoprecipitation of syndecan-I and NFI protein. Lane I: Keratinocyte cell lysate was immunoprecipitated with syndecan-I antibody. Western transfer analysis was carried out using NFIGRP(D) antibody. Lane 2: Parallel sample as in lane I, but without immunoprecipitation. Note typical $\sim 250$ $\mathrm{kDa}$ band representative of NFI protein in both samples.

and differentiation, including control of cytoskeletal organization and formation of cell-cell junctions $[7,14]$.

Western transfer analysis, immunolocalization and in situ hybridization showed that the NF1 gene was abundantly expressed in developing human epidermis. In contrast to adult epidermis, fetal basal cells displayed a fibrillar labeling pattern for NF1 protein between 8 and 14 weeks EGA. Later during the development, the fibrillar labeling of basal cells changed into a more diffuse cytoplasmic pattern. The fibrillar labeling pattern suggested that the NF1 protein was associated with cytoskeleton. Double immunolabelings demonstrated a relatively high degree of colocalization of NF1 protein and cytokeratin 14 at light microscopic level, and immunoelectron microscopy located NF1 protein on perinuclear keratin bundles. In developing human epidermis, NF1 protein did not show detectable association with actin microfilaments or tubulin, although in other studies and conditions, NF1 protein has been shown to interact with these cytoskeletal components [29].

Concomitantly with the association of NF1 protein to the cytokeratin, the epidermis undergoes profound changes: the stratification of epidermis, maturation of basement membrane zone, and the formation of desmosomes and hemidesmosomes is activated. At 9-16 weeks EGA, keratin filaments become more prominent, and the number of desmosomes increase [4]. First hemidesmosomes have 
been noted at $\sim 9$ weeks EGA. Between 9 and 15 weeks EGA the number of hemidesmosomes increases by about fourfold, and the morphology of hemidesmosomes matures simultaneously with increased contact with intermediate keratin filaments [2]. NF1 protein was detected also near the desmosomes and hemidesmosomes as indicated by both immunoelectron microscopy and double immunolabeling of NF1 protein with desmoplakin and $\beta 4$ integrin. These in vivo observations are in good agreement with the earlier in vitro study by Koivunen et al. [28]. They showed the association of NF1 protein with CK14-containing keratin intermediate filaments during the formation of desmosomes in cultured human keratinocytes. The present study demonstrates a similar association of NF1 protein and intermediate filaments during the formation of intercellular junctions in vivo. Developing epidermis thus provides a good model to study differentiation of keratinocytes in vivo, since the interactions of various cytoskeletal and junction proteins can be readily visualized.

The finding that NF1 specific antibodies raised against different peptide segments of the protein results in different labeling is in agreement with earlier studies $[20,21,28,33]$. Specifically, NF1GRP(D) antibody labeled most intensely the basal cells, while other antibodies used, NF1ab67 and NF1 as159, labeled all the developing cell layers indicating that NF1 protein is present in the intermediate cell layers, too. One plausible explanation is that NF1GRP(D) antibody may recognize only a specific type of NF1 protein conformation.

Expression of NF1 mRNA was studied at 13 and 18 weeks EGA using in situ hybridization. At 13 weeks, the localization of NF1 mRNA corresponded with the immunosignal for the NF1 protein. However, at 18 weeks, NF1 mRNA and protein displayed differential spatial distribution within the epidermis. Specifically, NF1 mRNA was detected in the suprabasal cells but not in the basal layer. Although NF1 protein remained detectable in the basal cells at 18 weeks EGA, the labeling pattern for NF1 protein in the basal cells had changed to a more diffuse cytoplasmic staining. It is thus possible that the more diffuse localization of NF1 protein in the basal cells is associated with downregulation of the NF1 mRNA level. These results are in concordance with previous studies detecting NF1 mRNA in suprabasal cell layers in late developing rat epidermis while basal cells contained no detectable NF1 mRNA at this stage of rat epidermal development [33].

NF1 mRNA was intracellularly distributed to the basal aspects of the basal cells and to the cell peripheries of intermediate cells at 13 weeks EGA. These are the sites where desmosome and hemidesmosome formation takes place during this stage of development. Previously, Ylä-Outinen et al. [31] have shown that NF1 mRNA is targeted to cell- cell contact zone in cultured human keratinocytes when they are induced to differentiate. This might be true also in vivo, since NF1 mRNA was accounted at cell-cell and cell-basement membrane contact zones.

Periderm cells showed profound changes in the expression pattern of NF1 protein. Our study revealed that, at 8 weeks EGA, when the desmosome formation is active in the periderm, the periderm cells showed fibrillar labeling for NF1 protein. By the 11th week of EGA, labeling for NF1 protein revealed a more diffuse pattern in the periderm cells, diminished thereafter, and disappeared by the 16 th week EGA. This correlates with the cessation of periderm cell proliferation at about 12 weeks EGA [3] and disruption of intermediate keratin filaments at 15-17 weeks EGA [4]. After the periderm cells cease dividing, they synthesize little if any protein and are gradually shed into the amniotic fluid by the end of the third trimester [3]. The expression of NF1 protein in the periderm thus correlates well with the periderm cell proliferation and cell junction forming activity. This is also in concordance with previous study on developing rat skin demonstrating NF1 protein first in the basal and periderm cells, but later mostly in the spinous cell layer [33].

Even though a bipartite interaction between transmembrane syndecans and NF1 protein has been characterized in neurons by two hybrid method [30], the results of the present study demonstrated only little of potential colocalization of NF1 protein and syndecan-1 in epidermal keratinocytes during the development and in adult. Thus, the conditions when NF1 protein and syndecans may interact, and the cell biological significance of this interaction remain to be elucidated.

\section{List of abbreviations}

BSA, Bovine serum albumin; CLSM, confocal laser scanning microscopy; EGA, estimated gestational age; GAP, Gprotein activating protein; NF1, type 1 neurofibromatosis; PBS, phosphate buffered saline; SDS, sodium dodecyl sulphate.

\section{Competing interests}

None declared.

\section{Authors' Contributions}

MM carried out the Western transfer analysis, indirect immunofluorescence labelings, confocal laser scanning microscopy, immunoelectron microscopy, and avidin-biotin immunolabelings. She also participated in drafting the manuscript. JK carried out keratinocyte cell cultures and coimmunoprecipitation, and participated in Western transfer analysis. SP and JP conceived of the study, drafted the manuscript, and participated in the design of the study. All authors read and approved the final manuscript. 


\section{Acknowledgements}

This work was supported by Turku University Foundation, Turku University Central Hospital (grant \# |3338), Oulu University Hospital, Finnish Cultural Foundation, Finnish Cancer Societies, and Finnish Society of Dermatopathology.

\section{References}

I. Holbrook KA, Odland GF: The fine structure of developing human epidermis: light, scanning, and transmission electron microscopy of the periderm. J Invest Dermatol 1975, 65:16-38

2. McMillan JR, Eady RA: Hemidesmosome ontogeny in digit skin of the human fetus. Arch Dermatol Res 1996, 288:91-97

3. Holbrook KA: Development of human skin. Retinoids 1997, I 3:47-53

4. Dale BA, Holbrook KA, Kimball JR, M Hoff, Sun TT: Expression of epidermal keratins and filaggrin during human fetal skin development. / Cell Biol 1985, I 0 I: | 257-1269

5. Hentula M, Peltonen J, Peltonen S: Expression profiles of cell-cell and cell-matrix junction proteins in developing human epidermis. Arch Dermatol Res 2001, 293:259-267

6. Pummi K, Malminen M, Aho H, Karvonen SL, Peltonen J, Peltonen S: Epidermal tight junctions: ZO-I and occludin are expressed in mature, developing, and affected skin and in vitro differentiating keratinocytes. J Invest Dermatol 200 I, I I 7:1050-1058

7. Vasioukhin V, Bauer C, Degenstein L, Wise B, Fuchs E: Hyperproliferation and defects in epithelial polarity upon conditional ablation of $\alpha$-catenin in skin. Cell 200I, 104:605-6I 7

8. Gutmann DH, Wood DL, Collins FS: Identification of the neurofibromatosis type I gene product. Proc Natl Acad Sci U S A 1991, 88:9658-9662

9. Gutmann DH, Aylsworth A, Carey JC, Korf B, Marks J, Pyeritz RE, Rubenstein $A$, Viskochil D: The diagnostic evaluation and multidisciplinary management of neurofibromatosis $I$ and neurofibromatosis 2. JAMA 1997, 278:5।-57

10. Marchuk DA, Saulino AM, Tavakkol R, Swaroop M, Wallace MR, Andersen LB, Mitchell AL, Gutmann DH, Boguski M, Collins FS: cDNA cloning of the type I neurofibromatosis gene: complete sequence of the NFI gene product. Genomics I99 I, I I:93 I-940

II. Riccardi VM: Von Recklinghausen neurofibromatosis. $N$ Engl Med 1981, 305: 1617-1627

12. Xu GF, Lin B, Tanaka K, Dunn D, Wood D, Gesteland R, White R, Weiss $R$, Tamanoi $F$ : The catalytic domain of the neurofibromatosis type I gene product stimulates ras GTPase and complements ira mutants of $S$. cerevisiae. Cell 1990, 63:835-84I

13. Bollag G, McCormick F: Ras regulation. NF is enough of GAP. Nature 1992, 356:663-664

14. Mercer JA: Intercellular junctions: downstream and upstream of Ras? Semin Cell Dev Biol 2000, I I:309-3 I4

I5. Legius E, Marchuk DA, Collins FS, Glover TW: Somatic deletion of the neurofibromatosis type I gene in a neurofibrosarcoma supports a tumour suppressor gene hypothesis. Nat Genet 1993, 3:122-126

16. Li Y, Bollag G, Clark R, Stevens J, Conroy L, Fults D, Ward K, Friedman E, Samowitz W, Robertson M: Somatic mutations in the neurofibromatosis I gene in human tumors. Cell I 992, 69:275281

17. Johnson MR, Look AT, DeClue JE, Valentine MB, Lowy DR: Inactivation of the NFI gene in human melanoma and neuroblastoma cell lines without impaired regulation of GTP-Ras. Proc Natl Acad Sci U S A 1993, 90:5539-5543

18. Gutmann DH, Geist RT, Rose K, Wallin G, Moley JF: Loss of neurofibromatosis type I (NFI) gene expression in pheochromocytomas from patients without NF I. Genes Chromosomes Cancer 1995, 13:104-109

19. Gutmann DH, Giordano MJ, Mahadeo DK, Lau N, Silbergeld D, Guha A: Increased neurofibromatosis I gene expression in astrocytic tumors: positive regulation by p2I-ras. Oncogene 1996, 12:2121-2127

20. Hermonen J, Hirvonen O, Ylä-Outinen H, Lakkakorpi J, Björkstrand AS, Laurikainen L, Kallioinen M, Oikarinen A, Peltonen S, Peltonen J: Neurofibromin: expression by normal human keratinocytes in vivo and in vitro and in epidermal malignancies. Lab Invest 1995, 73:221-228
21. Peltonen J, Karvonen SL, Ylä-Outinen H, Hirvonen O, Karvonen J: Lesional psoriatic epidermis displays reduced neurofibromin immunoreactivity. J Invest Dermatol 1995, 1 05:664-667

22. Aaltonen V, Boström PJ, Söderström KO, Hirvonen O, Tuukkanen J, Nurmi $M$, Laato $M$, Peltonen J: Urinary bladder transitional cell carcinogenesis is associated with down-regulation of NFI tumor suppressor gene in vivo and in vitro. Am J Pathol 1999 I 54:755-765

23. Brannan $\mathrm{Cl}$, Perkins AS, Vogel KS, Ratner N, Nordlund ML, Reid SW, Buchberg AM, Jenkins NA, Parada LF, Copeland NG: Targeted disruption of the neurofibromatosis type-I gene leads to developmental abnormalities in heart and various neural crestderived tissues. Genes Dev 1994, 8: 1019-1029

24. Daston MM, Ratner N: Neurofibromin, a predominantly neuronal GTPase activating protein in the adult, is ubiquitously expressed during development. Dev Dyn 1992, I 95:216-226

25. Hirvonen $\mathrm{O}$, Lakkakorpi J, Aaltonen V, Hirvonen H, Rossi M, Karvonen SL, Ylä-Outinen H, Kalimo H, Peltonen J: Developmental regulation of NFI tumor suppressor gene in human peripheral nerve. I Neurocytol 1998, 27:939-952

26. Baizer L, Ciment G, Hendrickson SK, Schafer GL: Regulated expression of the neurofibromin type I transcript in the developing chicken brain. I Neurochem 1993, 6 I:2054-2060

27. Huynh DP, Nechiporuk T, Pulst SM: Differential expression and tissue distribution of type I and type II neurofibromins during mouse fetal development. Dev Biol |994, I 6 I:538-55 |

28. Koivunen J, Ylä-Outinen H, Korkiamäki T, Karvonen SL, Pöyhönen M, Laato M, Karvonen J, Peltonen S, Peltonen J: New function for NF I tumor suppressor. J Invest Dermatol 2000, I I 4:473-479

29. Li C, Cheng Y, Gutmann DA, Mangoura D: Differential localization of the neurofibromatosis I (NFI) gene product, neurofibromin, with the F-actin or microtubule cytoskeleton during differentiation of telencephalic neurons. Brain Res Dev Brain Res 200I, I 30:231-248

30. Hsueh YP, Roberts AM, Volta M, Sheng M, Roberts RG: Bipartite interaction between neurofibromatosis type I protein (neurofibromin) and syndecan transmembrane heparan sulfate proteoglycans. J Neurosci 200 I, 2 I:3764-3770

31. Ylä-Outinen H, Koivunen J, Nissinen M, Björkstrand AS, Paloniemi M, Korkiamäki T, Peltonen S, Karvonen SL, Peltonen J: NF I tumor suppressor mRNA is targeted to cell-cell contact zone in $\mathbf{C a}^{2+}$ induced keratinocyte differentiation. Lab Invest 2002, 82:353361

32. Hirvonen O, Lakkakorpi J, Aaltonen V, Hirvonen H, Rossi M, Karvonen SL, Ylä-Outinen $\mathrm{H}$, Kalimo $\mathrm{H}$, Peltonen J: Developmental regulation of NFI tumor suppressor gene in human peripheral nerve. J Neurocytol 1998, 27:939-952

33. Malhotra R, Ratner N: Localization of neurofibromin to keratinocytes and melanocytes in developing rat and human skin. J Invest Dermatol 1994, 1 02:812-818

\section{Pre-publication history}

The pre-publication history for this paper can be accessed here:

http://www.biomedcentral.com/1471-5945/2/10/prepub

Publish with BioMed Central and every scientist can read your work free of charge

"BioMedcentral will be the most significant development for disseminating the results of biomedical research in our lifetime."

$$
\text { Paul Nurse, Director-General, Imperial Cancer Research Fund }
$$

Publish with BMC and your research papers will be:

- available free of charge to the entire biomedical community

- peer reviewed and published immediately upon acceptance

- cited in PubMed and archived on PubMed Central

- yours - you keep the copyright 